\title{
Exercise but not methacholine differentiates asthma from chronic lung disease in children
}

\author{
S Godfrey, C Springer, N Noviski, Ch Maayan, A Avital
}

\begin{abstract}
Bronchial provocation challenges with exercise and methacholine were performed on the same day or within a short interval in 52 children with asthma, 22 with other types of chronic lung disease (including cystic fibrosis), and 19 control subjects with no evidence of chronic lung disease. There were no significant differences in the baseline lung function before the two types of challenge in the individual groups and differences between the patients with asthma and with chronc lung disease were minor. When the mean -2 SD of the methacholine response of the control group was taken as the lower limit of normal, $49 / 52(94 \%)$ patients with asthma and $18 / 22(82 \%)$ with chronic lung disease responded abnormally. In contrast, with the mean +2 SD of the exercise response of the control group as the upper limit of normal, $41 / 52(79 \%)$ asthmatic patients responded but none of those with chronic lung disease. Thus the response to the two types of challenge helps to distinguish asthma from other types of chronic lung disease in children.
\end{abstract}

Asthma is the most common important chronic disease of childhood and affects 10$20 \%$ of all school age children. ${ }^{1-5}$ It is not, however, the only chronic lung disease of childhood or the only chronic lung disease to cause chronic airway obstruction. Other important conditions causing chronic lung disease in children include cystic fibrosis, the immotile cilia syndrome, postviral bronchiolitis obliterans, and bronchiectasis. Bronchial hyperreactivity to non-specific stimuli, such as inhalation of methacholine or histamine, exercise, isocapnic hyperventilation, or inhalation of non-isotonic fogs, is generally regarded as an important hallmark of asthma $a^{6-10}$; it has even been suggested that the lack of a positive response to methacholine invalidates the clinical diagnosis. ${ }^{11}$

Increased bronchial reactivity to exercise and bronchoconstrictor mediators has, however, been reported in children with cystic fibrosis ${ }^{12-15}$ and in adults increased reactivity to constrictor mediators has been found in normal subjects and some adults with chronic bronchitis and various other conditions, as pointed out by Britton and Tattersfield. ${ }^{16}$ These authors concluded that "it seems inherently unlikely that bronchial challenge tests will provide a clear distinction between asthmatic and non-asthmatic subjects." Ramsdale and colleagues, ${ }^{17}{ }^{18}$ however, showed that adults with chronic bronchitis and asthma were hyperresponsive to methacholine inhalation but in general only the asthmatic subjects responded to isocapnic hyperventilation.

Hyperreactivity to inhaled constrictor mediators may differ in its pathophysiological pathway from that of exercise or hyperventilation and these differences might be clinically relevant. We therefore compared reactivity to methacholine and exercise in children with asthma and other forms of chronic lung disease.

\section{Methods}

Ninety three young subjects, 78 under 16 years and 15 children aged 16-24, attending the pediatric respiratory diseases clinic underwent methacholine and exercise challenges during January 1989-July 1990. The patients were not selected specifically for the study and had been referred by their physician for investigation of lung function. For the purpose of the present analysis they were divided into three groups according to the clinical diagnosis established at not less than two visits to the clinic and in most cases by several visits over several months. Pertinent clinical details are given in table 1 . The asthmatic group consisted of 52 subjects (mean age 11.7 (SD 3.9) years, eight over 16 years) with a typical history, reversible airways obstruction documented by lung function testing, and a response to antiasthma medication. All had a normal chest radiograph between attacks and no evidence of other lung disease. The chronic lung disease group consisted of 22 children (mean age $11 \cdot 4(3 \cdot 1)$ years, two over 16$)$, seven of whom had cystic fibrosis, five unexplained recurrent pneumonia but no evidence of immunodeficiency or other underlying cause, six chronic obstructive lung disease following documented or presumed adenoviral bronchiolitis, two bronchiectasis, and two the immotile cilia syndrome.

The diagnosis was established in each child, by appropriate investigations, including sweat tests, computed tomography, nasal mucosa biopsy, and a trial of antiasthma medication to which there was no response. The control group consisted of 19 children (mean age 14.4 (4.1) years, five over 16), who had presented with chronic cough but in whom investigation and follow up failed to show any evidence of organic lung disease and in whom all symptoms disappeared. Lung function at rest was 
Table 1 Details of the three groups

\begin{tabular}{llrc}
\hline Group & Treatment/diagnosis & $n$ & Mean (SD) age (y) \\
\hline Control & & 19 & $14 \cdot 4(4 \cdot 1)$ \\
Asthma & Bronchodilator & 28 & \\
& Sodium cromoglycate & 6 & \\
& Sustained release theophylline & 5 & $11 \cdot 7(3 \cdot 9)$ \\
& Inhaled corticosteroids & 7 & \\
Chronic lung disease & Corticosteroids and theophylline & 6 & \\
& Cystic fibrosis & 7 & \\
& Postviral bronchiolitis obliterans & 6 & \\
& Recurrent pneumonia & 5 & $11 \cdot 4(3 \cdot 1)$ \\
& Immotile cilia syndrome & 2 & \\
& Bronchiectasis & 2 & \\
\hline
\end{tabular}

normal in 17 of these subjects and the presumed diagnosis was psychogenic cough. In one there was a minor reduction in the forced expiratory volume in one second $\left(\mathrm{FEV}_{1}\right)$ and in another a minor reduction in both FEV $_{1}$ and forced vital capacity (FVC). The omission of these two subjects made no difference to the results of the study. The control group was significantly older than the other two groups but there was considerable overlap. There was no difference in age between the asthmatic children and those with chronic lung disease.

Bronchial provocation tests using methacholine and exercise were performed on the same day in 39 of the 52 of the asthmatic children, 14 of the 22 children with chronic lung disease, and 17 of the 19 control children. The challenges were performed within one week in the remaining patients apart from five, in whom the interval was within two weeks. The methacholine was usually performed first ( 49 of the 52 asthmatic subjects, 18 of the 22 with chronic lung disease, and 17 of the 19 control subjects). The interval between challenges performed on the same day was normally one and a half hours, which was usually enough to allow the $\mathrm{FEV}_{1}$ to return to within $10 \%$ of the baseline value of the first challenge. In only seven instances (all from the asthma group) did the prechallenge baselines differ by more than $10 \%$ and in two of these instances the challenges were on different days. The baseline $F E V_{1}$ was more than $10 \%$ higher before the methacholine challenge in four instances and before the exercise challenge in three. The results of the exercise and methacholine challenges were not known to the investigator (SG) who allocated the children to the three diagnostic groups: he worked from the case notes without reference to the laboratory records.

Bronchial challenges were performed only if resting $\mathrm{FEV}_{1}$ was at least $60 \%$ of predicted. In the asthmatic patients all bronchodilator medications other than theophylline preparations were omitted for at least eight hours before the challenges and sodium cromoglycate for at least 12 hours. Theophylline and corticosteroids were continued in normal doses throughout both challenges. All the control subjects and all but one of the children with chronic lung disease were not being treated with antiasthma medication on a regular basis and had not received any medication for at least 24 hours before the challenges. One patient with the immotile cilia syndrome was being treated with slow release theophylline and inhaled corticosteroids at the time of the challenges as she had been thought to have asthma and the nasal mucosa biopsy result was not yet available. The reason for the tests was explained to the parents and the child, whose consent was obtained in conformity with the normal practice of this institution.

\section{METHACHOLINE CHALLENGES}

Methacholine was administered by the method described by Cockroft et $a l^{19}$ for adults. Increasing concentrations of methacholine were given for two minutes during tidal breathing, with measurement of lung function for three minutes after each inhalation. The inspirate was generated by a nebuliser (Hudson Up-draft Nebulizer, Temecula, California) connected to a CR 60 compressor (Medic-Aid Ltd, Pagham, UK) with an airflow rate of $6 \mathrm{l} / \mathrm{min}$. The nebuliser chamber was filled with $2.0 \mathrm{ml}$ of freshly prepared methacholine solution. Under the conditions of the test the nebuliser chamber decreased in weight by an average of $0.28 \mathrm{~g}$ in two minutes. The nebuliser was connected through a one way valve system to a mouth piece, through which the child breathed while wearing a nose clip. Lung function was measured with a pneumotachograph based system (Vitalograph Compact, Buckingham, UK), the highest value of $F E V_{1}$ recorded from two or three efforts being used.

Phosphate buffer (placebo) was inhaled initially and all subsequent changes in $F E V_{\text {, }}$ were related to the post-buffer value. The initial methacholine concentration $(0.03$ $\mathrm{mg} / \mathrm{ml}$ ) was followed by doubling concentrations until the $\mathrm{FEV}_{1}$ had fallen by more than $20 \%$ or the concentration of $8.0 \mathrm{mg} / \mathrm{ml}$ had been given. The concentrations of methacholine causing a $20 \%$ fall in $\mathrm{FEV}_{1}$ from the post-placebo value $\left(\mathrm{PC}_{20}\right)$ were derived from a plot of $\mathrm{FEV}_{1}$ on log methacholine concentration. If the $\mathrm{FEV}_{1}$ had not fallen by $20 \%$ after the $8.0 \mathrm{mg} / \mathrm{ml}$ dose a $P_{20}$ of $16 \mathrm{mg} / \mathrm{ml}$ was assigned.

\section{EXERCISE CHALLENGE}

All subjects carried out exercise for six minutes on a treadmill as described previously. ${ }^{20}$ The treadmill was set with a slope of $10^{\circ}$ and the subjects ran continuously at a speed of 5 $\mathrm{kph}$. This produced a heart rate of $160-180 /$ minute and represented about two thirds of the physical work capacity. $\mathrm{FEV}_{1}$ (the highest of two or three measurements) was measured before exercise and three, five, 10, 15, and 20 minutes afterwards. The challenge was performed in an air conditioned laboratory and the subject breathed room air with a temperature of $22-26^{\circ} \mathrm{C}$ and a relative humidity of $48-56 \%$. The climatic conditions did not vary systematically between the challenges in the different groups. The result of the exercise challenge was calculated as the greatest fall in $\mathrm{FEV}_{1}$ after exercise expressed as a percentage of the pre-exercise baseline value $\left(\Delta \mathrm{FEV}_{1}\right)$. 
Table 2 Lung function and reactivity to exercise and methacholine in the three groups

\begin{tabular}{|c|c|c|c|c|c|c|}
\hline & \multicolumn{2}{|l|}{ Control } & \multicolumn{2}{|l|}{ Asthma } & \multicolumn{2}{|c|}{ Chronic lung disease } \\
\hline & Exercise & Methacholine & Exercise & Methacholine & Exercise & Methacholine \\
\hline$n$ & \multicolumn{2}{|c|}{19} & \multicolumn{2}{|c|}{52} & \multicolumn{2}{|c|}{22} \\
\hline Baseline* & & & & & & \\
\hline $\mathrm{FEV}_{1}(\%)$ : mean & $88 \cdot 4$ & $89 \cdot 3$ & $84 \cdot 8$ & $86 \cdot 1$ & $79 \cdot 8$ & $79 \cdot 0$ \\
\hline $\mathrm{SD}$ & $9 \cdot 1$ & $8 \cdot 2$ & $10 \cdot 6$ & $9 \cdot 8$ & 12.9 & $13 \cdot 3$ \\
\hline \multicolumn{7}{|l|}{ Baseline } \\
\hline $\mathrm{MEF}_{50}(\%)$ : mean & $87 \cdot 9$ & $91 \cdot 4$ & $69 \cdot 2$ & $71 \cdot 1$ & 70.9 & $72 \cdot 8$ \\
\hline SD & $23 \cdot 1$ & $20 \cdot 1$ & $21 \cdot 1$ & $21 \cdot 1$ & $27 \cdot 6$ & $26 \cdot 5$ \\
\hline$\Delta \mathrm{FEV}_{1}(\%)+:$ mean & 1.9 & - & $25 \cdot 6$ & - & $2 \cdot 0$ & - \\
\hline SD & $3 \cdot 1$ & - & $18 \cdot 4$ & - & $4 \cdot 2$ & - \\
\hline $\mathrm{PC}_{20}(\mathrm{mg} / \mathrm{ml})_{+}^{+}:$mean & - & $10 \cdot 06$ & - & 0.33 & - & $1 \cdot 38$ \\
\hline$+1 S D$ & - & $19 \cdot 60$ & - & 1.21 & - & $4 \cdot 13$ \\
\hline$-1 \mathrm{SD}$ & - & $5 \cdot 17$ & - & 0.09 & - & 0.46 \\
\hline
\end{tabular}

*Forced expiratory volume in one second $\left(\mathrm{FEV}_{1}\right)$ and mid expiratory flow rate $\left(\mathrm{MEF}_{50}\right)$ expressed as $\%$ predicted.

$+\triangle \mathrm{FEV}$, after exercise expressed as \% baseline.

${ }_{+}$Provocative concentration of methacholine causing a $20 \%$ fall in $\mathrm{FEV}_{1}\left(\mathrm{PC}_{20}\right)$ expressed as the numerical equivalent of the mean log value and log SD.

\section{STATISTICAL ANALYSIS}

$\mathrm{PC}_{20}$ values were log transformed before statistical analysis and presented as geometric mean values with standard deviation. Statistical comparisons between groups and within groups were made by means of analysis of variance (ANOVA) and paired $t$ tests as appropriate. The Bonferroni correction was applied to the results for multiple comparisons between groups. Differences were taken as significant when $\mathrm{p}$ was less than 0.05 .

\section{Results}

The mean (SD) values for baseline $\mathrm{FEV}_{1}$ and maximum mid expiratory flow rate $\left(\mathrm{MEF}_{50}\right)$, $\mathrm{PC}_{20}$ methacholine, and $\Delta \mathrm{FEV}_{1}$ after exercise for the three groups are given in table 2 . Individual values for $\mathrm{PC}_{20}$ methacholine and $\Delta$ $\mathrm{FEV}_{1}$ after exercise are plotted in figures 1 and 2.

There was no significant difference in resting $\mathrm{FEV}_{1}$ before the exercise and methacholine challenges in any group. The group with chronic lung disease had significantly lower

\section{Methacholine Challenge}

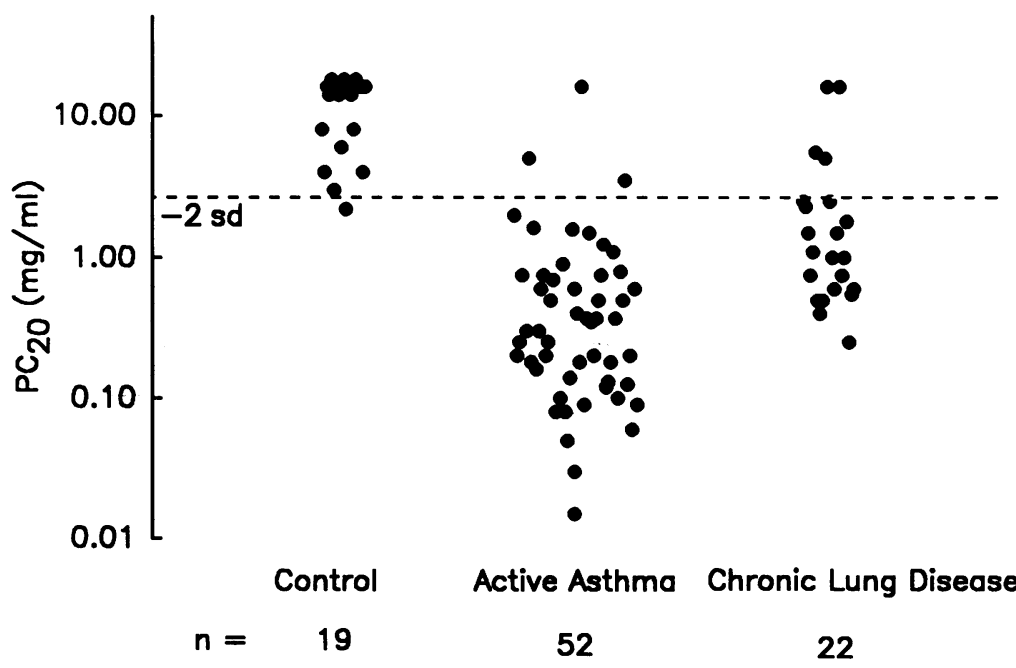

Figure 1 Individual values for $P C_{20}$ (provocative concentration of methacholine causing a $20 \%$ fall in $F E V_{1}$ ) in the three groups plotted on a log scale. The horizontal dashed line shows the lower limit of normal as the mean $-2 S D$ derived from the control group.
$\mathrm{FEV}_{1}$ values before both challenges than the control group and both the asthmatic patients and those with chronic lung disease had significantly lower maximum mid expiratory flow rates $\left(\mathrm{MEF}_{50}\right)$ than the control group before the challenges.

Although the mean $\mathrm{PC}_{20}$ methacholine values in the three groups differed very significantly (ANOVA, p $<0.0001$ ), there was considerable overlap between the values seen in those with asthma and in those with chronic lung disease. The mean $\Delta \mathrm{FEV}_{1}$ also differed very significantly between the groups (ANOVA, $p<0.0001$ ), but in this case there was very little overlap between the asthmatic children and the other two groups.

A normal range of response for each challenge was calculated from the results of the control group (see figs 1 and 2). The lower limit of normal for $\mathrm{PC}_{20}$ methacholine was taken as the mean minus $2 \log \mathrm{SD}(2.66 \mathrm{mg} / \mathrm{ml})$ and the upper limit of normal for $\triangle \mathrm{FEV}_{1}$ as the mean plus 2 SD $(8 \cdot 2 \%)$. In the asthmatic group 49 of the 52 subjects $(94 \%)$ had a $P_{20}$ below the lower limit of normal, as did 18 of the 22 subjects $(82 \%)$ with chronic lung disease. The $\triangle \mathrm{FEV}_{1}$ after exercise was greater than the upper limit of normal in 41 of the 52 asthmatic subjects $(79 \%)$, but none of those with chronic lung disease had a $\Delta \mathrm{FEV}_{1}$ after exercise that was above the normal range.

\section{Discussion}

In the present study bronchial hyperreactivity to methacholine was present in most of the young people with asthma or chronic lung disease, whereas hyperreactivity to exercise was present only in those with asthma. We know of no similar comparison of bronchial responsiveness to methacholine and exercise in children with asthma and in other chronic lung diseases. Previous studies have compared the sensitivity of asthmatic children to these different challenges and in general have found, as we did, that $90 \%$ or more responded to bronchoconstrictor mediators, such as methacholine or histamine, ${ }^{78}$ and about $75-80 \%$ responded to exercise. ${ }^{2122}$ Children with cystic fibrosis are reported to show increased responsiveness to both bronchoconstrictor mediators and exercise, ${ }^{12-15}$ though the increased respon- 


\section{Exercise Challenge}

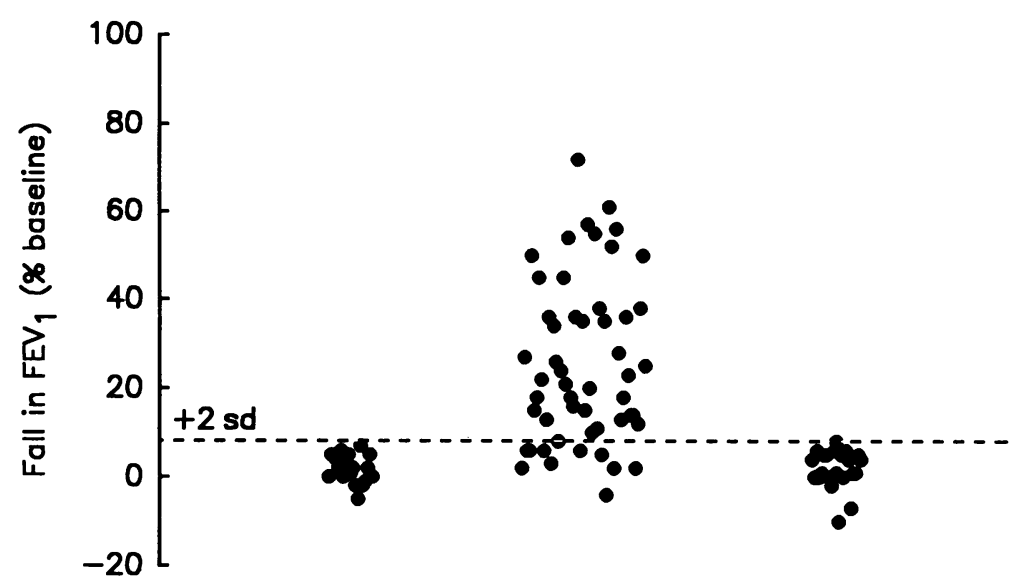

$n=\begin{array}{ccc}\text { Control } & \text { Active Asthmo } & \text { Chronic Lung Disease } \\ 19 & 52 & 22\end{array}$

Figure 2 Individual values for the change in forced expiratory volume in one second ( $\Delta$ $\left.F E V_{1}\right)$ in the three groups. The horizontal dashed line shows the upper limit of normal as the mean $+2 S D$ derived from the control group.

siveness to exercise consists mainly of an increase in $\mathrm{FEV}_{1}$ during exercise rather than a fall in $\mathrm{FEV}_{1}$ after exercise. ${ }^{13-15}$ The latter is characteristic of exercise induced asthma whereas the former could simply reflect release of bronchomotor tone or catecholamine secretion during exercise. ${ }^{14}$ In studies of adults with chronic bronchitis and asthma Ramsdale and her colleagues ${ }^{1718}$ found that 19 of 27 subjects with chronic bronchitis responded to histamine whereas only three of 27 responded to isocapnic hyperventilation. All 27 asthmatic subjects responded to methacholine and 26 of the 27 responded to isocapnic hyperventilation. These results from different studies of asthmatic adults, children with cystic fibrosis, and adults with chronic bronchitis are similar to those in the present investigation.

We considered whether any technical or design factors could have influenced the results of the present study. Resting lung function was similar and relatively good in the asthmatic subjects and the children with chronic lung disease and there was no correlation between resting lung function and the response to either challenge. The relatively good resting lung function meant that the children could have responded to a bronchoconstricting stimulus, and as it was very similar before each type of challenge in each group differences in lung function could not explain the difference in response to methacholine and exercise between those with asthma and those with chronic lung disease. In all groups most subjects underwent methacholine challenge before exercise challenge, and as the asthmatic subjects responded to exercise when this was preceded by methacholine challenge the methacholine challenge is very unlikely to have caused the lack of response in the children with chronic lung disease. Only one subject with chronic lung disease was taking antiasthma medication and her response did not differ from those of the 21 patients not taking medication. In contrast, several of the asthmatic patients were taking sustained release theophylline preparations, inhaled corticosteroids, or both $(5,7$, and 6 respectively). Inhaled corticosteroids have been shown to reduce bronchial reactivity whereas the effect of theophylline is more equivocal $^{23-27}$; yet 17 of the 18 patients still responded to methacholine and 15 to exercise. Our control group consisted of 19 subjects in whom no pulmonary disease could be found. The reactivity of these children to both methacholine and exercise was well within the normal range reported in other studies using the same techniques. ${ }^{819-21}$ By taking a difference of $2 \mathrm{SD}$ to define normality we maximised the chance of a sick child falling within the normal range.

Despite much work the pathogenesis of exercise induced asthma is still disputed. ${ }^{28}$ There now seems little doubt that cooling or drying of the airways, or both, together with an exercise or hyperventilation related factor, act as the trigger mechanism. The effector mechanism is thought to be contraction of airway smooth muscle, though it has been suggested that reactive hyperaemia could cause the airways obstruction. ${ }^{29}$ There are, however, arguments against this, ${ }^{28} 30$ including the fact that bronchoconstriction often occurs during exercise before the airways have had time to rewarm. The intermediary pathway between stimulus and effect is less certain but circumstantial evidence suggests that chemical mediators may play a part. ${ }^{31-33}$ Methacholine and histamine are presumably acting mainly on bronchial smooth muscle. They could, in theory, also trigger mediator release but a rise in one mediator (neutrophil chemotactic factor) has not been recorded in the response to challenge with histamine or methacholine and the response to these stimuli is not blocked by sodium cromoglycate. ${ }^{32} 33$ The difference between exercise on the one hand and methacholine and histamine on the other may lie in the presence of an intermediary pathway for a response to exercise but not to methacholine or histamine, while the final common pathway, airway smooth muscle contraction, is similar.

Increased responsiveness of bronchial smooth muscle could result from several factors, including damage to the bronchial epithelium from any cause, exposing subepithelial nerve endings and removing epithelium derived relaxant factor..$^{34}$ Such damage occurs in asthma but also occurs with other chronic inflammatory processes in the airways; transient bronchial hyperreactivity can be induced by the inhalation of ozone or other pollutants that damage the mucosa. Such a mechanism could explain the hyperreactivity to methacholine seen in our patients with chronic lung disease. If, on the other hand, exercise induced asthma depended on an intermediary pathway specific to asthma, an abnormal response to exercise would be expected only in asthma whereas an abnormal response to methacholine would be seen in both asthma and chronic lung disease. Increased responsiveness to histamine has been found in subjects with previous asthma but no symptoms at a time when they no longer respond to 
exercise, ${ }^{36}{ }^{37}$ which suggests that "growing out of asthma" might depend on a loss or diminution of the intermediary pathway. We cannot explain why $21 \%$ of our asthmatic patients failed to respond to exercise, though this is similar to the proportion of non-responders reported by others. ${ }^{21}$ The factors that influence the net effect of an exercise challenge on an asthmatic patient include, among others, climatic conditions, presence or absence of allergenic stimulation, pollution levels, and medications; so some unpredictability is to be expected.

In our study bronchial hyperresponsiveness to methacholine was common to all kinds of chronic lung disease in childhood, whereas an abnormal response to exercise occurred only in asthma. Although the response to exercise in asthma was not universal ( $79 \%$ responded), the use of both types of challenge helps in the differential diagnosis of asthma and other types of chronic lung disease in children.

Williams $\mathrm{H}, \mathrm{McNicol} \mathrm{KN}$. Prevalence, natural history and relationship of wheezy bronchitis and asthma in children. An epidemiological study. $B M J 1969$;iv:321-5.

2 Lee DA, Winslow NR, Speight AN, Hey EN. Prevalence and spectrum of asthma in childhood. $B M$ 1983;286:1256-8.

3 Speight ANP, Lee DA, Hey EN. Underdiagnosis and undertreatment of asthma in childhood. $B M J$ 1983;286:1253-6.

4 Asher MI, Pattemore PK, Harrison AC, et al. International comparison of the prevalence of asthma symptoms and bronchial hyperresponsiveness. Am Rev Respir Dis 1988;138:524-9.

5 Richards W. Hospitalization for children with status asthmaticus: A review. Pediatrics 1989;84:111-8.

6 Parker CD, Bilbo RE, Reed CE. Methacholine aerosol as test for bronchial asthma. Arch Intern Med 1965;115:452-8.

7 Townley RG, Bewtra AK, Nair NM, Brodky FD, Watt GD, Burke KM. Methacholine inhalation challenge studies. Allergy Clin Immunol 1979;64:569-74.

8 Juniper EF, Frith PA, Hargreave FE. Airway responsiveness to histamine and methacholine: relationship to minimum treatment to control symptoms of asthma. Thorax 1981;36:575-9.

9 Godfrey S. Stimuli to bronchoconstriction-basic mechanisms. Israel J Med Sci 1982;18:297-306.

10 Anderson SD, Schoeffel RE, Finney M. Evaluation of ultrasonically nebulised solutions for provocation testing in patients with asthma. Thorax 1983;38:284-91.

11 Pratter MR, Hingston DM, Irwin RS. Diagnosis of bronchial asthma by clinical evaluation. An unreliable method. Chest 1983;84:42-7.

12 Counahan R, Mearns MB. Prevalence of atopy and exerciseinduced bronchial lability in relatives of patients with cystic fibrosis. Arch Dis Child 1975;50:477-81.

13 Price JF, Weller PH, Harper SA, Matthew DJ. Response to bronchial provocation and exercise in children with cystic fibrosis. Clin Allergy 1979;9:563-70.

14 Skorecki K, Levison H, Crozier DN. Bronchial lability in cystic fibrosis. Acta Paediatr Scand 1976;65:39-44.

15 Holzer FJ, Olinsky A, Phelan PD. Variability of airways hyperreactivity and allergy in cystic fibrosis. Arch Dis Child 1981;56:455-9.

16 Britton J, Tattersfield AE. Does measurement of bronchial hyperreactivity help in clinical diagnosis of asthma. Eur $J$ Respir Dis 1986;68:233-8.

17 Ramsdale EH, Morris MM, Roberts RS, Hargreave FE. Bronchial responsiveness to methacholine in chronic bronchitis: relationship to airflow obstruction and cold air responsiveness. Thorax 1984;39:912-8.

18 Ramsdale EH, Roberts RS, Morris MM, Hargreave FE. Differences in responsiveness to hyperventilation and methacholine in asthma and chronic bronchitis. Thorax 1985;40:422-6.

i9 Cockcroft DW, Killian DM, Mellon JJA, Hargreave FE. Bronchial reactivity to inhaled histamine: a method and clinical survey. Clin Allergy 1977;7:235-43.

20 Anderson SD, Silverman M, Konig P, Godfrey S. Exerciseinduced asthma. Br J Dis Chest 1975;69:1-39.

21 Mellis CM, Kattan M, Keens TG, Levison H. Comparative study of histamine and exercise challenges in asthmatic children. Am Rev Respir Dis 1978;117:911-5.

22 Fourie PR, Joubert JR. Determination of airway hyperreactivity in asthmatic children: A comparison among exercise, nebulised water and histamine challenges. Pediatr Pulmonol 1988;4:2-7.

23 Shapiro G, Phillips JJ, Smith K, Furukawa CT, Pierson WE, Bierman CW. Effectiveness of terbutaline and theophylline alone and in combination in exerciseinduced bronchospasm. Pediatrics 1981;67:508-13.

24 Henriksen JM. Effect of inhalation of corticosteroids on exercise induced asthma: randomised double blind crossover study of budesonide in asthmatic children. $B M J$ 1985;291:248-9.

25 Magnussen $H$, Reuss G, Jorres R. Theophylline has a doserelated effect on the airway response to inhaled histamine and methacholine in asthmatics. Am Rev Respir Dis and methacholine

26 Jenkins CR, Woolcock AJ. Effect of prednisone and beclomethasone dipropionate on airway responsiveness in asthma: a comparative study. Thorax 1988;43:378-84

27 Tinkelman DG, Bikramjit SG, Lutz CN. Relationship of different serum levels of theophylline on methacholine sensitivity. J Allergy Clin Immunol 1990;85:750-5.

28 Anderson SD, Daviskas E, Smith CM. Exercise-induced asthma: a difference in opinion regarding the stimulus. Allergy Proc 1989;10:215-26.

29 McFadden ER. Hypothesis: exercise-induced asthma as a vascular phenomenon. Lancet 1990;335:880-3.

30 Godfrey S. Exercise-induced asthma as a vascular phenomenon [Letter]. Lancet 1990;335:1410-1.

31 Godfrey S. Controversies in the pathogenesis of exercise induced asthma: Annotation. Eur J Respir Dis 1986;68: 81-8.

32 Lee TJ, Brown MJ, Nagy L, Causon R, Walport MJ, Kay $\mathrm{AB}$. Exercise induced release of histamine and neutrophil chemotactic factor in atopic asthmatics. J Allergy Clin Immunol 1982;70:73-81.

33 Lee TH, Nagy $L$, Nakagura $T$, Walport MJ, Kay AB. Identification and partial characterization of an exerciseinduced neutrophil chemotatic factor in bronchial asthma. Induced neutrophil chemotatic

34 Hargreave FE, Dolovich J, O'Byrne PM, Ramsdale EH, Daniel EE. The origin of airway hyperresponsiveness. $J$ Allergy Clin Immunol 1986;78:825-32.

35 Barnes PJ. New concepts in the pathogenesis of bronchia hyperresponsiveness and asthma. $J$ Allergy Clin Immunol 1989;83:1013-26.

36 Martin AJ, Landau LI, Phelan PD. Lung function in young adults who had asthma in childhood. Am Rev Respir Dis 1980;122:609-16.

37 Chatham M, Bleecher ER, Smith PL, Rosenthal RR, Mason P, Norman PS. A comparison of histamine, methacholine and exercise airway reactivity in control and asthmatic subjects. Am Rev Respir Dis 1982;126:235-40. 